\title{
Young disabled and LGBT+: Negotiating Identity
}

\section{Introduction}

Within popular discourse, the journey from child to adult is conceptualised in terms of change and uncertainty. This is often referenced in relation to the development of personal identity and the formation of a 'self'. The increased emphasis on maturity and independence represents a shift to individual autonomy with young people taking control of their own lives. Indeed, within the literature on sexuality and gender in the lives of disabled people, adolescence is presented as a time of "social exploration, identification, self-identity building and the establishment of core social values' (Corker, 2001, p.91). It is clear that for young people who are trying to make sense of their place in the world, it is important to have a sense of their identity and what this means in relation to wider society. For young people who are disabled and LGBT+, this is particularly nuanced as they are subjected to dual discrimination and layered stigma (McCann, Lee \& Brown, 2016).

This article will show how young disabled LGBT+ people understand their identities against the backdrop of societal misconceptions which threaten to undermine them. Throughout, the focus will be upon the experiences and views of disabled young people themselves and how they negotiate and enact their identities despite these challenges. The stories of disabled young people guide this article; in line with our goal to amplify the voices of a group of marginalised young people. Although the period of adolescence and young adulthood is important in terms of identity development, research has not adequately engaged with disabled young people to explore LGBT+ sexuality and gender. Yet large populationbased studies have shown $17 \%$ of young transgender people are disabled (Jones et al 2015) and a similar number of same-sex attracted young people are disabled (Hillier et al 2010). 
Following a brief overview of existing literature, the article outlines the definitions and concepts that we have used in order to be clear and transparent in this regard. The article then moves to outline the methods we adopted to conduct the research, highlighting the innovative ways we engaged with young people, but also clearly outlining the limitations of the research and our goals for continued work in this area. Three thematic areas will then be presented under the heading 'findings' enabling the article to explore how the young people 'do' their identities: Perceptions; exploring societal understandings and the impact upon the young people's lives. Negotiations; focussing upon the strategies used and ways of understanding identity. Enactments; how these processes are adapted and practiced; how identity is 'done' in everyday life.

\section{Research with young disabled LGBT+ people}

Research exploring sexuality and gender in the lives of disabled young people who identify as LGBT+ is scarce. In a recent review of the literature, Wilson et al. (2016) refer to the "total absence" (p.4) of research involving children, youth, and the elderly with intellectual disability (author term). Some existing studies might also be considered damaging as they compare the sexual behaviours of disabled and nondisabled LGBT+ people (Cheng \& Udry, 2002) and portray specific impairment groups as sexually 'weird' or 'abnormal' (Hellemans, Roeyers, Leplae, Dewaele \& Deboutte, 2010). Such research continues to 'other' the experiences of disabled LGBT+ people, denying the validity of disabled sexuality and gender identity.

Societal perceptions suggest that disabled people are incapable of having sexual desires and romantic relationships (Dinwoodie, Greenhill \& Cookson, 2016), and caregivers and service providers who support disabled young people find the subject uncomfortable (Abbott \& Howarth, 2007). Furthermore, there is an underlying concern that encouraging 
disabled young people to explore their sexuality would put them at risk (Blyth \& Carson, 2007). Disabled people are more likely to be a victim of sexual violence (Mencap, 2001); however, the idea that the vulnerability associated with disability increases the likelihood of becoming a victim of sexual violence is an oversimplification of a complex issue (Hollomotz, 2009). Research suggests that the overprotection of this group and a lack of support in helping them to explore their sexuality and gender identity safely can result in disabled children and young people having sexual relationships in secret and being open to sexual exploitation; such sheltering and 'infantilising' of disabled young people can mean that they are not adequately prepared for adult life (Franklin \& Smeaton, 2017).

The idea that young disabled people are social actors who have a sexual identity and identify as LGBT+ is likely to challenge the common rhetoric where disabled people are considered to be vulnerable and in need of protection. There is a continual debate surrounding the challenges of upholding rights and the need for protection; if disabled young people are considered by society and those who care for and work with them to be 'childlike' in their abilities (Corker, 2001), then having a sexual relationship is likely to challenge this. Some also contend that disabled young people who demonstrate any sexual intent are going through a 'phase', or deem it to be part of the disability (Corker, 2001). Recent research by Richards (2017) which explored the poetry of one gay man with a learning disability (authors term), described how society is ignorant to the sexual desires and identities of people with learning disabilities. Stauffer-Kruse (2007) argued that gay men with learning disabilities (authors term) are particularly vulnerable when it comes to parents and carers repressing their need to sexual expression, which can lead to behaviour which is subsequently defined as challenging. The sexuality of disabled young people with complex needs in particular is suppressed by parents, teachers, and service providers (Blanchett \& Wolfe, 2002). Ongoing practices surrounding hormone treatments and sterilisation also reflect the 
concern of society that disabled women (note these are the authors terms) are not capable of being "good" parents (Tilley, Walmsley, Earle \& Atkinson, 2012) and feeds into wider debates about eugenics. While in the UK disabled women have a right to say what happens to their bodies, research indicates that they still play a passive role in decision-making (McCarthy, 2009). McCarthy (2009) found that contraception was prescribed at an earlier age and continued to be prescribed later than with non-disabled women, and non-sexually active disabled women were given contraceptives "just in case".

The construction of identity in relation to a young person's sexuality, gender and disability is important as adolescence and young adulthood is a crucial time for identity development. Research in this area indicates that young people prioritise their sexuality rather than disability when constructing their identity (Shakespeare, Gillespie-Sells \& Davies, 1996). Chappell (2014) found that young people did not explicitly discuss disability in relation to their sexual identity unless prompted, while aspects such as gender and culture were prominent in discussions about love and relationships. This is considered to be in contrast to how society views young disabled people, defining them by their impairment, with their sexuality perceived to be non-existent in their lives (Corbett, 1994).

\section{Definitions and concepts}

The participants in the research are referred to as 'young people' throughout, however, it should be clear that they are in fact young disabled LGBT+ people and such a shortening is for ease of reporting.

When discussing individual participants and using gender pronouns we use the pronoun used by the participants themselves.

LGBT+ is used as a catch-all term to represent sexualities/genders other than heterosexual which are non-normative within the current societal context. We accept that 
identities falling under the ' + ' of this acronym are visibly hidden. However, this is done as LGBT+ was the preferred term used by the group of young people we worked with and also for ease of reporting. It is not a reflection of the debate regarding what should be included within the acronym. It is clear that the identities within the acronym face different challenges and negotiations; Toft \& Yip (2018) for example showed the different negotiations for bisexuals. With such exploratory work it is important that there is a collective voice. This is also the case for the use of the phrase 'young disabled and LGBT+' or 'disabled young people'. There is no implication of hierarchy with this use of language and it has been adopted for ease of reading only.

The research was guided by a model which locates disability in the social, cultural, material and attitudinal barriers that exclude people with impairments from mainstream society. We note this here to distinguish the approach from a medical model.

\section{Methods and analysis}

This paper presents data from a project exploring sexuality/gender identity in the lives of 13 young (16-25 years), disabled, LGBT+ people. The aim was to amplify the voices of this marginalised group. Semi-structured individual interviews were conducted via two groups of young people at two different sites in central UK: a LGBT+ youth group (7 young people) and a specialist disability college (6 young people), after recruitment using known contacts. The sample was small and convenient, and results may not be generalizable. We can only, of course, speak about the experiences of the participants. However, the depth of the data can add to understandings of the challenges highlighted in the literature and the way that the participants worked to negotiate their identities. Disabled young people with complex communication needs were not included in the research as a result of this recruitment. We continue to develop our inclusive methods to enable this group to take part in our further 
research. As a result, the sample included young people with a wide-range of intellectual disabilities (including what are sometimes called learning disabilities), autistic spectrum conditions and mental health needs.

Interviews were deemed appropriate for providing a safe space for discussion and have been effectively used in previous work which has explored sexual inequalities with disabled young men (Blyth \& Carson, 2007). A semi-structured interview schedule was developed based on the key themes which emerged from the review of the literature. Questions were open-ended and flexible, encouraging the young person to direct the conversation. Questions explored their experiences of being LGBT + and disabled, their views on how they were perceived by wider society, family, school and other institutions with which they were engaged if appropriate (e.g. Church), and how they worked against the challenges of enacting their identities.

The interview was also supported by a selection of participatory activities designed to support interview themes and to improve accessibility. Activities such vignettes or role play situations reduced the need to constantly question and answer, which can be particularly anxiety-inducing. Such vignettes presented stories of disabled LGBT+ from news sources to encourage comment and wider thinking. We presented scenarios or stories and asked participants how they would respond to situations of discrimination. The overall aim alongside encouraging engagement was to explore the challenges the participants faced and what they did to negotiate their identities as a result. We found that such activities were useful ice-breakers which encouraged participants to think about some of the wider issues that the interview would explore.

Interviews lasted around one hour and were audio recorded to allow the interviewer to focus upon the conversation and to enable transcription. All interviews were held in a private space either at the youth group or the college. The information sheet and consent form 
provided explained the ethical principles that the research team would uphold such as confidentiality, data protection, and withdrawal. All information was presented orally alongside the written documents. Consent was taken prior to the interview taking place. The project was approved by the University's ethics committee.

For each interview we looked for common themes using thematic analysis - a flexible and widely used qualitative data analysis tool (Braun \& Clarke, 2006). The research team took time to reflect upon the themes generated and crosschecked them collectively.

We have taken a broadly intersectional approach to understanding identity (see Crenshaw, 1991). Its use as a heuristic tool continues to gain in popularity within the social sciences. Although it could be seen as unwieldy and imprecise as a theoretical framework, its basic underlying features, specifically the importance to consider how identities intersect and impact, and how power and imbalance is different for people who possess different identities; it is a useful tool which is relevant in the lives of young disabled LGBT+ people. In accepting this and understanding that such intersections are important, we used it to highlight the challenges the participants faced and how they negotiated and enacted their identities. Important understandings such as Goffman's Presentation of the Self (1959), queer theory (Chappell, 2015) and Layder's (2004) theories of selfhood are also important in understanding how such marginalised identities are negotiated.

\section{Findings}

The findings have been organised into three themes: perceptions, negotiations, and enactment of identity. In reality such processes are overlapping and in a state of constant flux, however for clarity we use such categorises to explore the common and recurrent challenges in which the young people participated. In exploring 'perceptions' we can discover how the young people felt others view them in society. 'Negotiations' then considers how the young people 
internalise and reconcile these perceptions. Lastly 'enactments' explores how the young people 'do' or 'enact' their identity in public spheres.

\section{Perceptions}

How the young people felt others perceived them and their response to this was a core theme from the interviews. Throughout the discussions two interconnecting processes emerged concerning their experiences of societal perceptions: desexualisation and infantilisation. Such processes relate to underlying societal misconceptions about disabled sexuality and gender identity, which is further reflected in disabled young people being denied access to information/education. Blyth and Carson (2007) have argued it is inaccurate to assume that talking to young disabled people about sexuality encourages sex in potentially risky situations. Denying access to education only maintains this cycle of underprotection and overprotection (Franklin \& Smeaton, 2017).

For young disabled LGBT+ people desexualisation is rooted in an understanding of them as non-sexual, often in combination with an underestimation of their abilities and a low expectation of their contribution to society. Bridget explained this tension and how she actively worked to dispel it:

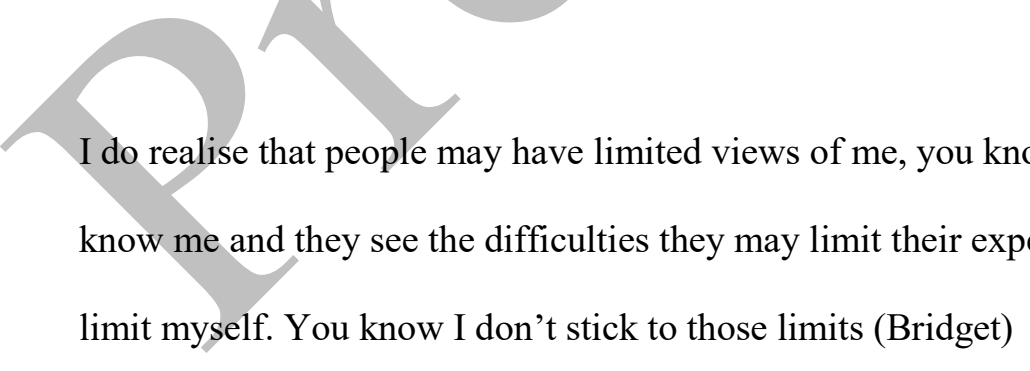

In addition to lowering expectations, the young people described how they were patronised and treated as being younger than they were. This was a source of frustration for a number of the young people including Edith who was in her twenties: 
...Some people are trying to be nice but come across as really, really patronising when they find out that you have autism, it's like 'are you ok?' and I'm like 'yes. I'm not a small child! Thank you!' It's like, just because I struggle with some things like dates and times doesn't mean that I cannot do things (Edith)

Edith's experiences reflect the infantilisation of disabled young people. Corker's (2001) work is important to consider here as she suggested that young people are viewed as inferior or not to be taken seriously. The process of infantilisation has resulted in a perception that LGBT+ is a phase, whereby being LGBT+ was seen as a temporary position which would change as the person grows and matures:

...People tend to, you know, [say] you're still young, they think you could change, they think you could just turn and do whatever. [They say] 'Oh you're not sure that you're gay yet?' (Bridget)

This was also expressed by young people who were trans:

When I was a younger person and I came out mum always used to tell me it was a phase and I would grow out of it, in competitions she would put make-up on me and I used to tell her that wasn't fancy dress. It was how I wanted to live (Abigail)

Here Abigail is expressing frustration that although she is clear about self-identity, this is not being respected or accepted by a parent. The idea of sexuality and gender identity as a phase is related to the age and perceived competency of young people, informed by Western constructions of what it means to be an adult. Dominant discourses view children and young people as 'becomings' who are not capable of knowing what is best for them 
(Wyness, 2012). This is likely to be extended to adults who have a disability as discourses are still predominantly one of protection and provision, rather than agency. Within this framework, the decision for a disabled young person to question their sexuality and/or gender identity will be seen as ill-informed and perhaps even whimsical. This is likely to be far from the case, as many of the young people described how they had reflected on their sexuality and gender identity for many years before coming out to others. Furthermore, the response from parents that the young people will 'grow out' of their sexuality or gender identity suggests that there is something undesirable about being LGBT+. This is reflected in queer theory in the work of Ahmed (2006) who points out that heterosexuality is idealised in our society and is framed as the correct projection towards monogamy and family life. Queer sexualities as a result are positioned as the other and that which is undesirable.

For another young person, James, these limiting societal perceptions and stereotypes of disabled people influenced thoughts about his own life:

...Growing up have always had a fear that I personally would become a person who would end up being 40 still living with his parents, alone in the basement kind of thing, because that has been a big stereotype of what people with disabilities and autism are (James)

It is clear that societal perceptions and stereotypes can be extremely powerful in shaping what an individual thinks they can expect to achieve in their life. At a time when young people are trying to understand who they are and shape who they want to be they are surrounded by negativity which limits expectations and paints a bleak future. As a result James has a 'fear' of being old and alone. Society tells disabled young people that they are not to expect the same opportunities and experiences as their non-disabled peers, which is daunting prospect for someone who is young and has their life ahead of them. 
There was a common feeling among the young people that even if society accepts them as sexual beings, they must be straight:

People don't expect you to have that interest, and even if they did would presume that you're straight because it's not generally advertised that disabled people can be gay, they can be transgender, people are just blind to it (Bridget)

The quotation from Bridget highlights the lack of discussion surrounding disability, sexuality and gender identity. Although Bridget slips into using ableist language here ('blind to it') she is indicating that others are either unaware that disabled people can be LGBT+, or that they are actively choosing to ignore it. It is evident that there is a disconnection between how the young people view themselves and how they feel that society views them and treats them. Even before taking their sexuality, gender identity and age into account, there are challenges associated with others' perceptions of their capabilities as a disabled person. It is disheartening to learn that such perceptions still remain since Craft (1987, p.14, cited in Chappell, 2015) explored the idea of the 'forever child' in relation disabled people.

\section{Negotiations}

In light of the misconceptions outlined in the previous section, the young people had to work to make sense of who they are with limited support and guidance. Importantly, the young people were found to internalise societal perceptions and had to negotiate their place in the society. This section explores how the young people negotiate and reconcile identity in relation to wider societal perceptions; focussing upon the internal processes and negotiations that the young people practiced. We found that this was done in relation two aspects. Firstly, to challenge sex/gender labels and work to re-evaluate them; and secondly, usually as a result of this challenge, working to understand how their identities intersect. 


\section{Labels}

Many of the participants with autism were keen to distinguish between the labels associated with autism (i.e. autistic and Asperger's) and the 'disabled' label. They said that they would not use the word 'disabled' to describe themselves but this would be how society would label them and how they need to be viewed in order to receive certain benefits. Kaarim for example noted that he saw "it as a disability but I don't see myself as disabled"

It is interesting to reflect on the connotations associated with the word 'disabled'. For most of the young people this term was considered to be negative and linked to the low expectations they also described. However, the young people with mental health needs did not have such a negative view of being labelled as disabled because they were striving for their needs to be recognised as a disability. Amy, James and Wayne all discussed how still there is a lack of understanding that mental health difficulties are a 'real' disability and that general ignorance and disbelief is still present in society. Wayne in particular discussed how in the past they had been referred to as an 'attention-seeker', constantly having to validate the challenges that they are facing with their mental health.

A number of the young people described their dislike of labels and how they generally did not use them to describe themselves. This was the case with Adam who wanted to be defined by name and nothing else. Robert discussed how society uses labels to stereotype and put people into 'boxes', which can act to exclude people and make them feel like they are not good enough to belong.

I feel like [labels] kind of creates stereotypes and boxes and not everyone fits in them, so I feel like it just leaves people out and makes people feel not good enough maybe... (Robert) 


\section{Intersections}

Most of the young people faced barriers because of their disability but saw sexuality and gender identity as a central part of who they were. Crucially, most young people felt they had more control over their sexual/gender identity than their disabled identity because they could choose when and where to reveal it. This was different for trans young people, as hiding aspects of their gender identity was more challenging. Being trans was also considered to be less acceptable in the eyes of parents. Wayne described how his parents accepted when he came out as bisexual but not as trans:

I came out as a female who was bisexual and that went down fine, absolutely fine, and then I came out to my parents as trans, I had to move out (Wayne)

Some young people with autism perceived a link between autism and LGBT+ sexualities/genders. Edith discussed how people with autism are more gender-fluid in regards to gender due to not always understanding or living by socially-constructed gender ideals:

...Being autistic, obviously you don't see things like other people do and you don't latch onto societal norms as easily...I never really knew what it was, I never really understood it, I’ve never felt a girl or boy because I just don't have any concept of those things (Edith)

Similar comments were given by others like Bridget, who believed that she is nonbinary and asexual due to their autism and would not be able to easily separate the identities:

I think that they interlock, you know, quite well, because there are studies that show that autistic people are more fluid gender-wise, they don't really care, so it is more likely that we are going to be gay or Trans... (Bridget) 
It was apparent that abstract and socially-constructed gender norms may be difficult to understand or are considered irrelevant in the lives of the autistic young people. Edith talked about how she just did not 'get' gender:

Mostly I just don’t get gender, I just find it very confusing, not confusing as I don't know but confusing as why do people have one of those, I just don't feel like I need one really (Edith)

However, for Kaarim, the identities were seen as separate and difficult to reconcile. Autism was perceived to act as a barrier to social engagement and not a desired aspect of who he is:

[Autism] does limit me. I feel that this [being gay] does not limit me because it is something that you identify with and shouldn't be discouraged, it is not stopping me from doing things (Kaarim)

It appears that Kaarim has internalised the message that being gay and having a disability is difficult for people to accept. It is also clear that Kaarim finds autism disabling and at odds with being gay. Kaarim also discussed how his family make links between the two identities in a negative way - using autism as an 'excuse' for being gay. This was incredibly frustrating for Kaarim who believed that he would be gay irrespective of whether he had autism or not:

...she [his sister] will use my disability as a reason for the way I am... she will kind of hide it with my disability and my past and stuff, to try and cover it up (Kaarim) 
The struggle that young disabled people experience in establishing and 'proving' themselves as a competent and sexual individual who identifies as LGBT+, could have implications for their identity development and wellbeing. Although the contemporary focus is to explore the individualisation of identity and the rise of personal agency, most clearly espoused by Bauman (2003), for young people who are working to establish who they are and where they fit, reliance on entirely self-projected identity appears to be flawed if one does not have any blueprints or role-models to aspire to. Layder (2004) theorises how our own self-acceptance and belief is not enough when constructing our self-identity, we must also feel like others approve of us and believe in us. If a young person feels that their sexuality or gender identity is continually 'disbelieved', this acts to invalidate their identity and could have long-term implications.

\section{Enactments}

This final section considers how the young people 'enact' their identity in public. Goffman's work on the presentation of the self (1959) suggests that what we choose to reveal about ourselves in public depends on what we think will be accepted by its members. Yet, this is in a state of negotiation because, as highlighted by Sedgewick (1994) it is often incorrectly assumed that self-identity should match performance of identity and this should remain constant over a lifetime. It is also important to consider that how young people enact their identity will be influenced by being both disabled and LGBT+ (Chappell, 2015).

Intersectional frameworks perceive identity to cross the boundaries of socially constructed groups, with social categories interlocking and reinforcing one another (Choo \& Ferree, 2010; McCall, 2005), which can result in "layered oppressions" (Santiele Martino, 2017, p.9). 
The experiences of the young people show that 'doing' identity was most salient during coming out journeys, when accessing safe spaces and when in public.

\section{Coming out}

A recurring theme was how the young people felt they needed to hide or suppress certain aspects of their identity at certain points in their lives. Many described how prior to 'coming out' they had concealed their sexuality or gender identity from their family and friends, with some still hiding this from their father or members of the extended family. Fear of rejection was discussed as the main reason for hiding their identities from family and friends, with all longing for acceptance and support. The young people's views in this regard clearly reflect a social trend highlighted by Chappell (2015) which suggests that those who do not embody normative sexual identities or indeed practices are marginalised and subjugated. One young person described how they still 'put on' an act when extended family visit, and Abigail explained how she had to hide aspects of her gender identity:

Well I am having to live as a male at home to please people. It is mainly my family where I change myself as a person to please them (Abigail)

For many, keeping aspects of identity private was a way of ensuring that they were safe. Discrimination and abuse had been experienced by many of the young people in school or college, with some continuing to experience such negative events as young adults, and so they had adopted this coping strategy. The young people who identified as trans had been severely targeted and as a result of their experiences were very wary of disclosing any information to others: 
I have been called a tranny, I've been told to slit my throat, slit my wrists, nobody wanted me here. I've been beat up a few times as well (Abigail)

The young people who were 'stealth' (perceived as cisgender) used this as a safety strategy to avoid abuse; however such an approach may not be possible for all.

I identify as what you call Stealth, which basically means I do not tell people that I am Trans, like I'm male and I've always been male, and that's what I tell them. So, for example one of my housemates, only one of them is aware who's my close friend, and the rest of them don't know (Wayne)

\section{Safe spaces}

Young people described the benefits of meeting up with others who were similar to them and had similar experiences. They described how structured groups in college and the youth group were places where the young people could be themselves:

When I'm at [support group] I can experiment with different clothing without being judged. I have done so before. Everyone is completely fine with it because we have a lot of Trans members and everyone is completely accepting of them. So me wearing something a bit different is nothing to them, oh another person just experimenting with gender and stuff (Aaron).

Such a space was a safe haven for many of the young people, further highlighting the importance of collective identity and the need for positive affirmation through common experience in the lives of young people: 
It's just like a support network, it's like I can be a bit more open about a central part of my identity without having to live in fear of like saying the wrong thing or doing the wrong thing (Wayne).

\section{Public life}

Many of the young people discussed how they adapted their identity and behaviour when in public. Young people commented that they found older generations to be less understanding and more judgemental. One young person, Edith, felt that very few people understood being non-binary and so it was easier to not engage in a conversation about it with those who do not know her well:

Unless I'm with a group or with my Mom, I held back a lot of the non-binary stuff because people don't get it...It's only close friends and relatives that know about my issues and my identity, I'm pretty safe and guarded (Edith)

Those with mental health conditions were less likely to reveal this aspect of their identity when meeting new people, due to past negative experiences. They felt that there was a stigma attached to mental health and that it might 'put off' potential partners who saw them as a 'bit of baggage' (James).

This could potentially link to the work of Green (2014) and the sexual fields framework which has been explored in relation to disability and sexuality by Santinele Martino (2017). James here perceives themselves to be baggage and as having limited sexual capital. Within their sexual field (further education) James asserts that their desirability is low and they have decided that their mental health places their ability to achieve social significance as precarious. Further analysis of how this sexual field is shaped in terms of its 
attitudes towards desire is necessary, yet it is clear that mental health and disability is represented as a low hierarchy of desire.

\section{Concluding Remarks}

The young disabled LGBT+ people we spoke to work hard to construct their identities against societal perceptions which are perpetuated through misconceptions about disability, sexuality and gender. The article has clearly shown that it is most fruitful to take an intersectional approach to youth, disability, sexuality and gender as they are intrinsically linked. For example, with the assertion that sexuality and gender identity is a phase it is important to understand that this is being projected onto young people because they are LGBT+ which is situated as the 'other' in heteronormativity, but also because the young people are young and framed as being immature and still exploring their identity; and also because they are disabled and seen as being incapable of understanding LGBT+ sexuality and gender. Such an approach ensures a fuller more nuanced understanding of experience. We conclude in reference to Santinele Martino (2017) that this approach will continue to advance knowledge and the rights of disabled LGBT+ people.

\section{References}

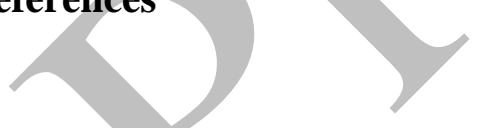

Abbott, D., \& Howarth, J. (2007). Still off-limits? Staff views on supporting gay, lesbian and bisexual people with intellectual disabilities to develop sexual and intimate relationships? Journal of Applied Research in Intellectual Disabilities, 20, 116-126.

Bauman, Z. (2003). Liquid Love. Cambridge: Polity Press. 
Blanchett, W. J., \& Wolfe, P. S. (2002). A review of sexuality education curricula: Meeting the sexuality education needs of individuals with moderate and severe intellectual disabilities. Research and Practice for Persons with Severe Disabilities, 27, 43-57.

Braun, V., \& Clarke, V. (2006). Using thematic analysis in psychology. Qualitative research in psychology, 3, 77-101.

Blyth, C., \& Carson, I. (2007). Sexual uncertainties and disabled young men: silencing difference within the classroom. Pastoral Care in Education, 25, 34-38.

Chappell, P. (2014). How Zulu-speaking youth with physical and visual disabilities understand love and relationships in constructing their sexual identities. Culture, health \& sexuality, 16, 1156-1168.

Chappell, P. (2015). Queering the social emergence of disabled sexual identities: Linking queer theory with disability studies in the South African context. Agenda, 29, 54-62.

Cheng, M. M., \& Udry, J. R. (2002). Sexual behaviors of physically disabled adolescents in the United States. Journal of Adolescent Health, 31, 48-58.

Corbett, J. (1994). A proud label: Exploring the relationship between disability politics and gay pride. Disability \& Society, 9, 343-357.

Corker, M. (2001). " Isn't that what girls do?"-disabled young people construct (homo) sexuality in situated social practice. Educational and Child Psychology, 18, 89-107. 
Crenshaw, K. (1991). Mapping the Margins: Intersectionality, Identity Politics, and Violence Against Women of Color. Stanford Law Review, 43, 1241-1299.

Dinwoodie, R., Greenhill, B., \& Cookson, A. (2016). 'Them two things are what collide together': understanding the sexual identity experiences of lesbian, gay, bisexual and trans people labelled with intellectual disability. Journal of Applied Research in Intellectual Disabilities. Advance online publication. doi:10.1111/jar.12252.

Franklin, A., \& Smeaton, E. (2017). Recognising and responding to young people with learning disabilities who experience, or are at risk of, child sexual exploitation in the UK. Children and Youth Services Review, 73, 474-481.

Goffman, E. (1959). The presentation of self in everyday life. NY: Garden City.

Green, A. I. (2014). The sexual fields framework 25-56. In Green, A. I. (Ed.). (2014). Sexual fields: Toward a sociology of collective sexual life. Chicago: University of Chicago Press.

Hellemans, H., Roeyers, H., Leplae, W., Dewaele, T., \& Deboutte, D. (2010). Sexual behavior in male adolescents and young adults with autism spectrum disorder and borderline/mild mental retardation. Sexuality and Disability, 28, 93-104.

Hillier, L., Jones, T., Monagle, M., Overton, N., Gahan, L., Blackman, J., \& Mitchell, A. (2010). Writing themselves in 3: The third national study on the sexual health and wellbeing of same sex attracted and gender questioning young people. Melbourne: ARCSHS. 
Hollomotz, A. (2009). Beyond 'vulnerability': An ecological model approach to conceptualizing risk of sexual violence against people with learning difficulties. British Journal of Social Work, 39, 99-112.

Jones, T., de Bolger, A. D. P., Dune, T., Lykins, A., \& Hawkes, G. (2015). Female-to-male (ftm) transgender people's experiences in Australia: A national study. London: Springer.

Layder, D. (2004). Social and personal identity: Understanding yourself. London: SAGE.

Levy, D. L., \& Reeves, P. (2011). Resolving identity conflict: Gay, lesbian, and queer individuals with a Christian upbringing. Journal of Gay \& Lesbian Social Services, 23, 53 68.

McCarthy, M. (2009). I have the jab so I can't be blamed for getting pregnant: Contraception and women with learning disabilities. Women's Studies International Forum, 32(3), 198-208.

McCann, E., Lee, R., \& Brown, M. (2016). The experiences and support needs of people with intellectual disabilities who identify as LGBT: a review of the literature. Research in Developmental Disabilities, 57, 39-53.

Mencap (National Society for Mentally Handicapped Children and Adults), Respond (Organization: London, England), \& Voice, U. K. (2001). Behind Closed Doors: Preventing Sexual Abuse against Adults with a Learning Disability. Mencap. 
Richards, M. (2017). Angry, when things don't go my own way': what it means to be gay with learning disabilities. Disability \& Society, 32, 1165-1179.

Santinele Martino, A. (2017). Cripping sexualities: An analytic review of theoretical and empirical writing on the intersection of disabilities and sexualities. Sociology Compass, 11, e12471.

Sedgwick, E.K. (1994). Tendencies. London: Routledge.

Shakespeare, T., Gillespie-Sells, K., \& Davies, D. (1996). The sexual politics of disability. London: Cassell.

Stauffer-Kruse, S. (2007). Gay men with learning disabilities: UK service provision. Journal of Gay \& Lesbian Psychotherapy, 11, 145-152.

Tilley, E., Walmsley, J., Earle, S., \& Atkinson, D. (2012). 'The silence is roaring': sterilization, reproductive rights and women with intellectual disabilities. Disability \& Society, 27, 413-426.

Toft, A., \& Yip, A. K. T. (2018). Intimacy negotiated: The management of relationships and the construction of personal communities in the lives of bisexual women and men.

Sexualities, 21(1-2), 233-250.

Wilson, N. J., Macdonald, J., Hayman, B., Bright, A. M., Frawley, P., \& Gallego, G. (2016). A narrative review of the literature about people with intellectual disability who identify as 
lesbian, gay, bisexual, transgender, intersex or questioning. Journal of Intellectual Disabilities, 22, 171-196.

Wyness, M. (2012). Childhood and society. London: Palgrave Macmillan.

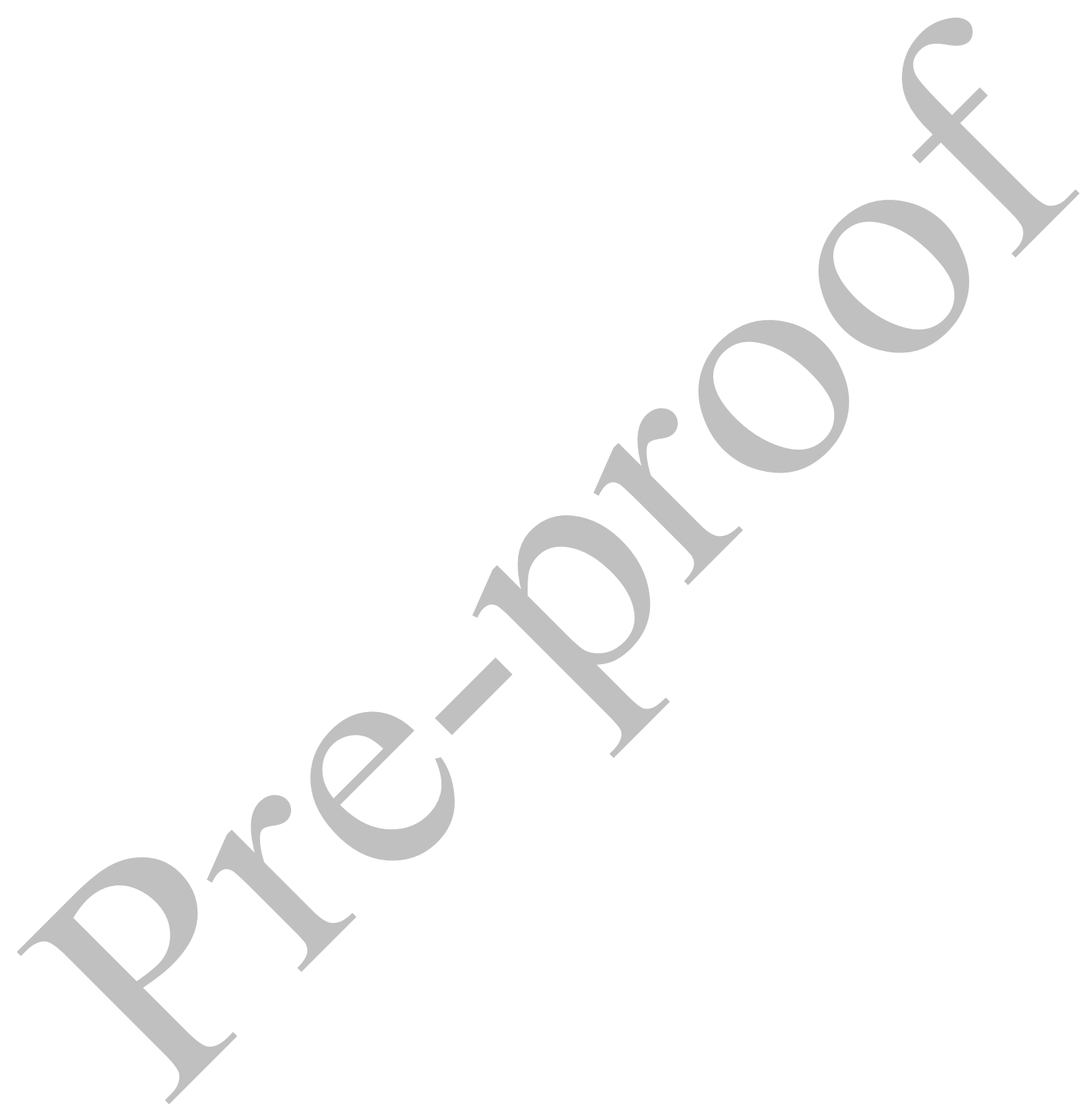

